\title{
Resonance-enhanced Multiphoton Ionization Time-of-Flight Mass Spectrometry for Evaluating Emulsion Inversion via Temperature Change
}

\author{
Masafumi IwATA and Tomohiro UCHIMURA ${ }^{\dagger}$ \\ Department of Materials Science and Engineering, Graduate School of Engineering, University of Fukui, \\ 3-9-1 Bunkyo, Fukui 910-8507, Japan
}

\begin{abstract}
This study used resonance-enhanced multiphoton ionization time-of-flight mass spectrometry (REMPI-TOFMS) to evaluate the phase inversion that is driven via temperature change. A change in temperature prompts phase inversion in an oil-in-water $(\mathrm{O} / \mathrm{W})$ emulsion that uses a nonionic surfactant as an emulsifier. In this study, an $\mathrm{O} / \mathrm{W}$ emulsion was prepared containing Triton X-100 as an emulsifier. To promote emulsion inversion, we heated only the outlet of a capillary column that was used for sample introduction during REMPI-TOFMS. When the emulsion was continuously measured at $40^{\circ} \mathrm{C}$, several intense spikes could be detected on a time profile for the analyte, toluene, constructed by extracting the peak areas from a series of obtained mass spectra. This indicated the presence of toluene droplets in the $\mathrm{O} / \mathrm{W}$ emulsion. No intense spikes appeared at $80^{\circ} \mathrm{C}$, however, which suggested the shrinkage or even disappearance of the oil droplets following phase inversion. Using this technique, an emulsion can be measured without affecting the influence of vaporization even at elevated temperatures, which surely is a serious concern when using other analytical techniques. Therefore, this technique would be quite useful for evaluating the phase inversion of an emulsion at elevated temperatures.
\end{abstract}

Keywords REMPI-TOFMS, O/W emulsion, phase inversion

(Received July 19, 2019; Accepted August 15, 2019; Advance Publication Released Online by J-STAGE August 23, 2019)

\section{Introduction}

An emulsion is a system where droplets of one liquid are dispersed in another with which it is immiscible. ${ }^{1}$ There are two basic types of emulsions: an oil-in-water $(\mathrm{O} / \mathrm{W})$ emulsion where oil is dispersed in water and a water-in-oil (W/O) emulsion where water is dispersed in oil. Surfactants are normally applied to emulsion products, such as cosmetics and inks. In the case of an $\mathrm{O} / \mathrm{W}$ emulsion using a nonionic surfactant as an emulsifier, the size of the oil droplets decreases with increasing temperatures,${ }^{2}$ which results in phase inversion as the emulsion changes to a W/O type through an intermediate stage. ${ }^{3,4}$ The phase-inversion temperature (PIT) ${ }^{5,6}$ is affected by several factors, such as the types of surfactants and additives. ${ }^{7,8}$ Not only the droplet size and size distribution, but other factors, such as turbidity, are changed during the process of emulsion inversion. Although the PIT emulsification process is commonly used for emulsion products, its mechanism is complicated and remains unclear. Several analytical methods, such as electrical conductivity, microscopy, and dynamic light scattering (DLS) are used for evaluating phase inversion driven by temperature change. ${ }^{9-11}$ It is difficult to measure the local microenvironment of an emulsion in detail; however, and questions persist for details, such as which phase each constituent occupies during the phase inversion process. In order to control emulsion inversion as intended, an analytical method for detailed

$\dagger$ To whom correspondence should be addressed.

E-mail: uchimura@u-fukui.ac.jp evaluation is needed.

Mass spectrometry (MS) is a powerful tool for both the qualitative and quantitative analysis of constituents in a sample. Recently, we reported on the online monitoring of constituents in an emulsion using resonance-enhanced multiphoton ionization time-of-flight mass spectrometry (REMPI-TOFMS). ${ }^{12-16}$ REMPI has superior optical selectivity and produces fewer fragment ions, ${ }^{17-20}$ which allows for the sensitive detection of a molecular ion within a mixture. TOFMS is a reasonably straightforward non-scanning type MS that allows the simultaneous detection of all induced ions, even when several types of analytes are present in a sample. REMPI-TOFMS is applied in a wide variety of fields, such as spectroscopic studies and environmental monitoring. ${ }^{21-28}$ This method is normally used for the detection of samples in the gas phase with fewer applications to liquid samples. ${ }^{29}$ In order to apply the unique features of this method to the measurement of an emulsion, we developed a sample introduction technique for REMPI-TOFMS that is based on the use of a pair of concentric capillaries. ${ }^{12}$

When using REMPI-TOFMS for the online monitoring of an emulsion, a series of mass spectra is recorded. In addition, the time profile of an analyte can also be obtained, which is constructed by extracting the peak area of an analyte from the spectra. The obtained time profiles are very informative. For example, we often find many spikes on the time profile of an oil phase in an $\mathrm{O} / \mathrm{W}$ emulsion with turbidity, and the appearance of spikes indicates that the emulsion contains oil droplets. ${ }^{30}$ Moreover, we have also reported on the quantifiable nature of this technique for an emulsion measurement, ${ }^{31}$ as well as its usefulness in the evaluation of emulsion creaming. ${ }^{32}$ 
In the present study, we proposed an analytical method based on REMPI-TOFMS to evaluate an emulsion where phase inversion occurs via temperature change. In preliminary studies using emulsions containing either a nonionic surfactant or an anionic surfactant, the types of emulsions were studied using a conductivity meter and a microscope. REMPI-TOFMS was then applied to the measurement of emulsions to explore the possibility of detecting an emulsion inversion. By only changing the temperature at the outlet of the sample introduction system, a change in the signals of the time profiles was confirmed, which provided important information concerning the existence of oil droplets.

\section{Experimental}

\section{Reagents}

The following reagents were all purchased from Wako Pure Chemical Industries (Osaka, Japan): toluene (purity above 99.8\%); a nonionic surfactant, polyoxyethylene(10)octylphenyl ether (Triton X-100, practical grade, hydrophilic-lipophilic balance $(\mathrm{HLB})=13.5) ;{ }^{33}$ an anionic surfactant, sodium dodecyl sulfate (SDS, first grade, purity above 95\%); glycerol (purity above $97.0 \%$ ) that decreases a cloud point ${ }^{8}$ and, Sudan III (special grade). Cyclohexane (purity above 99.5\%, boiling point $=81^{\circ} \mathrm{C}$ ) was purchased either from Wako Pure Chemical Industries or from Nacalai Tesque (Kyoto, Japan). Sodium chloride $(\mathrm{NaCl}$, purity above $99 \%$ ) was purchased from a local supermarket. Distilled water was produced in the laboratory.

\section{Sample preparation}

We prepared two types of emulsions by using either nonionic or anionic surfactants. The preparation procedure for an emulsion using a nonionic surfactant was as follows. Triton $\mathrm{X}-100(\mathrm{ca} .0 .6 \mathrm{~g})$ and glycerol $(1.0 \mathrm{~g})$ were added to distilled water $(14 \mathrm{~mL})$ in a $50-\mathrm{mL}$ sample container. The liquid sample was stirred at $600 \mathrm{rpm}$ using a magnetic stirrer (REXIM RS1DN, AS ONE, Osaka, Japan). Five minutes after the stirring was begun, cyclohexane $(5.4 \mathrm{~g})$ was added dropwise to the sample. The liquid sample was stirred for a total of $30 \mathrm{~min}$. A $3 \mathrm{wt} \%$ concentration of TritonX-100 was used, as suggested in a previous report. ${ }^{34}$ For the REMPI-TOFMS measurement, cyclohexane was mixed with toluene and added dropwise. In this case, the concentration of toluene was adjusted to $3.0 \mathrm{~g} / \mathrm{L}$ where the denominator of the unit was the sum of the volume of water and cyclohexane before mixing.

An $\mathrm{O} / \mathrm{W}$ emulsion that included an anionic surfactant was prepared as follows. First, SDS was dissolved in $25 \mathrm{~mL}$ of distilled water in a 50-mL sample container. The concentration of SDS was adjusted to $3.0 \mathrm{~g} / \mathrm{L}$ of water. Toluene was then added, and the liquid sample was homogenized at $5000 \mathrm{rpm}$ for 5 min (AHG-16D, AS ONE). The concentration of toluene was adjusted to $2.0 \mathrm{~g} / \mathrm{L}$ of water.

\section{Conductivity and microscopic measurements}

The phase condition of the emulsions was confirmed using a conductivity meter (CT-58101B, DKK-TOA, Tokyo, Japan). In this case, $\mathrm{NaCl}$ was dissolved in an aqueous solution, and then an oil phase was added. The concentration of $\mathrm{NaCl}$ was adjusted to $1 \mathrm{wt} \%$ that of the water. The tip of a conductivity meter probe was inserted $2 \mathrm{~cm}$ from the surface of the emulsion. In order to increase the temperature of the sample, the sample container containing an emulsion at room temperature was immersed into a water bath, the temperature of which was adjusted to $90^{\circ} \mathrm{C}$, while it was manually shaken. Measurements

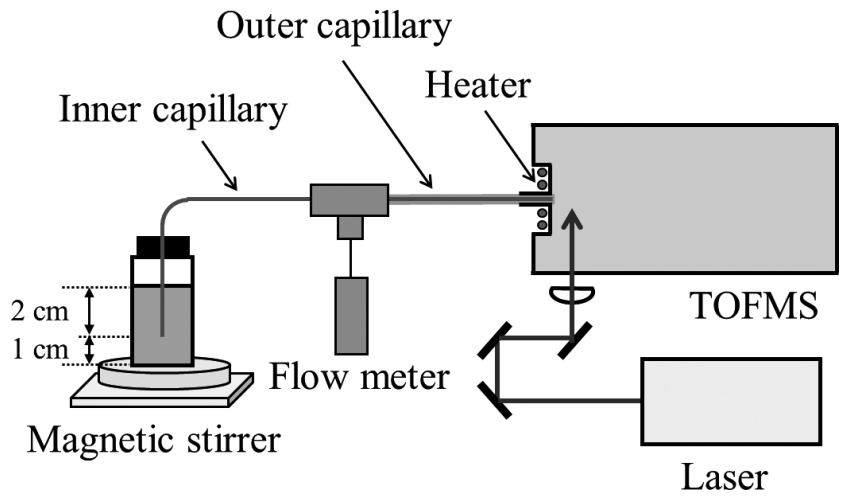

Fig. 1 Experimental apparatus for REMPI-TOFMS.

using a microscope or REMPI-TOFMS differed from conductivity measurements, which in this case were performed using an emulsion that was 10-times the amount needed to maintain a lower heating rate, in order to precisely detect a conductivity drop. ${ }^{35}$

The morphology of the emulsion droplets was observed using an inverted microscope (ECLIPSE, TE2000-U, Nikon, Tokyo, Japan) consisting of an objective (Plan Fluor, 20×, NA0.25, Nikon) and a digital camera (DIGITAL SIGHT, DS-U1, Nikon). In this case, a lipophilic dye, Sudan III ${ }^{36}$ was dissolved to an oil phase (cyclohexane or toluene) prior to the addition of the oil phase into a water phase. The concentration of the Sudan III was $5 \mathrm{mM}$ when in an oil phase. In this measurement, the temperature of the sample was increased from room temperature to 40 and $80^{\circ} \mathrm{C}$. The sample container of an emulsion was immersed into a water bath, the temperature of which was adjusted to $90^{\circ} \mathrm{C}$, for a certain time while it was manually shaken. Then, each heated sample was removed from the water bath for measurement. The actual temperature of each sample was considered to have slightly decreased during the measurement.

\section{REMPI-TOFMS}

Figure 1 features a schematic diagram of the experimental apparatus. Details of the REMPI-TOFMS used in the present study are reported elsewhere. ${ }^{12}$ Briefly, a pair of concentric fused-silica capillary columns (deactivated, GL Sciences, Tokyo, Japan) was used to achieve sample introduction. The length and inner/outer diameters of the inner capillary were $65 \mathrm{~cm}$ and $25 / 150 \mu \mathrm{m}$, respectively, and those of the outer capillary were $35 \mathrm{~cm}$ and $320 / 450 \mu \mathrm{m}$, respectively. The tip of the inner capillary column toward the TOFMS side was adjusted $2-3 \mathrm{~mm}$ inward from the tip of the outer capillary column. Emulsion samples were introduced through the inner column. The height of an emulsion sample in a 50-mL sample container was $c a .3 \mathrm{~cm}$, and the inner column was inserted to $1 \mathrm{~cm}$ from the bottom of the container. Ambient air was introduced through the outer column at $2 \mathrm{~mL} / \mathrm{min}$, which was adjusted using a flow meter (RK-1250, Kofloc, Kyoto, Japan).

The fourth-harmonic emission of a Nd:YAG laser (GAIA II, $10 \mathrm{~Hz}, 4 \mathrm{~ns}$, Rayture Systems, Tokyo, Japan) served as an ionization laser. The pulse energy was adjusted to $20 \mu \mathrm{J}$, and a plano-convex lens $(f=200 \mathrm{~mm})$ was used to focus the pulse. The ionization point was adjusted to a distance $2 \mathrm{~mm}$ from the tip of the outer capillary.

A sheathed heater was attached to a flange on the TOFMS and used to indirectly heat at least $9 \mathrm{~mm}$ of the sample introduction outlet. Later, we describe how we confirmed that the phase 
inversion of an emulsion was brought about by increasing the temperature at the sample introduction outlet. A description of the experimental procedure follows. First, until the temperature at the sample introduction outlet was increased from room temperature to $40^{\circ} \mathrm{C}$, an emulsion was gently stirred (at $400 \mathrm{rpm}$ ) in order to prevent creaming. When the temperature reached $40^{\circ} \mathrm{C}$, the stirring was stopped and an inner capillary column was inserted into the emulsion. The emulsion was let stand for $10 \mathrm{~min}$, and then recording of the mass spectra was started using a digitizer (AP240, $1 \mathrm{GHz}, 1 \mathrm{GS} / \mathrm{s}$, Acqiris/Agilent Technologies, Tokyo, Japan). After finishing the recording, the emulsion was again stirred at $400 \mathrm{rpm}$ until the temperature at the sample introduction outlet reached $80^{\circ} \mathrm{C}$. Again, the stirring was then stopped and the emulsion was left standing for another $10 \mathrm{~min}$, after which the emulsion was again measured. In the present study, the ionization laser was introduced $30 \mathrm{~s}$ after starting the recording in order to determine the zero baseline.

A time profile of the peak area for toluene was constructed by extracting the peak areas of both a molecular ion $(\mathrm{m} / \mathrm{z}, 92)$ and a fragment ion $(\mathrm{m} / \mathrm{z}, 91)$ from a series of obtained mass spectra. The signal intensities for each time profile were normalized by the entire peak area obtained from each time profile.

\section{Results and Discussion}

Evaluating the phase inversion via conductivity meter

The emulsion type can be estimated via conductivity. In most applications, some electrolytes are added to an emulsion, which should exist in an aqueous phase. An emulsion containing a nonionic surfactant changes from $\mathrm{O} / \mathrm{W}$ to $\mathrm{W} / \mathrm{O}$ via an increase in temperature. The continuous phase changes from an aqueous phase to an oil phase, and as a result, the conductivity of the emulsion is decreased.

Figure 2 shows the conductivity versus temperature profiles of emulsions prepared in the present study. The conductivities of the emulsion containing a nonionic surfactant, Triton X-100, showed higher values until $70^{\circ} \mathrm{C}$, and became very small at $80^{\circ} \mathrm{C}$. Therefore, the PIT of the emulsion was assumed to be $c a$. $75^{\circ} \mathrm{C}$. On the other hand, the conductivities of the emulsion containing SDS were unchanged with increasing temperature, which means that the emulsion was an $\mathrm{O} / \mathrm{W}$ type, even at elevated temperatures.

\section{Microscopic observation of the phase inversion}

Figure 3 shows phase-contrast images of an emulsion containing Triton X-100 at 40 and $80^{\circ} \mathrm{C}$; again, the actual temperature of each sample was considered to have slightly decreased during the measurement. As shown in Fig. 3(a), droplets were colored using Sudan III, while the continuous phase was not. This dye has a lipophilicity, which revealed that the emulsion was an $\mathrm{O} / \mathrm{W}$ type. At first glance, the emulsion seemed to be polydispersed; the diameters of the observed droplets seemed roughly compatible, perhaps lower, with the inner diameter of the inner capillary column $(25 \mu \mathrm{m})$.

In contrast, the image in Fig. 3(b) was colored through the entire field of view, and the droplets could not be clearly visualized. The droplet size of an emulsion is known to decrease during the process of phase inversion when the temperature increases. ${ }^{4}$ In this experiment, it was difficult to distinguish the phase type of the emulsion after heating, but at least it was not the same $\mathrm{O} / \mathrm{W}$ type observed at $40^{\circ} \mathrm{C}$. Needless to say, further increases in the temperature would have been counterproductive for observation, since the influences of vaporization and successive boiling of the sample solution were valid
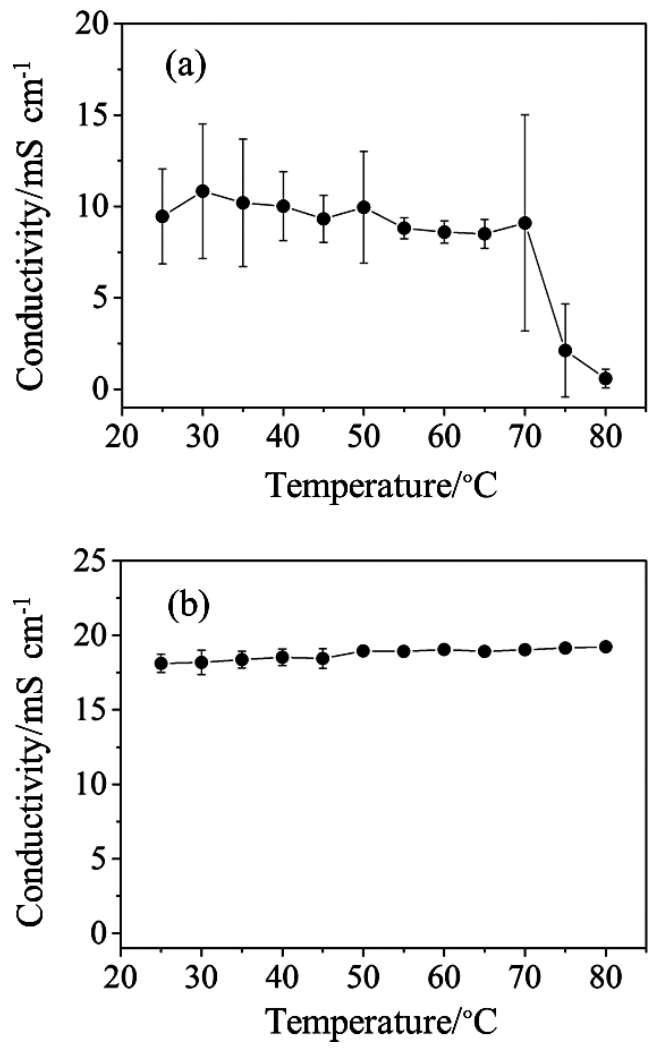

Fig. 2 Conductivity versus temperature of the emulsions. Emulsifier: (a) Triton X-100 ( $n=4)$, (b) SDS $(n=3)$.

considerations.

As a control experiment, an emulsion containing an anionic surfactant, SDS, was also observed (Fig. 4). As a result, emulsion droplets were colored in either case. Therefore, as expected, both emulsions were O/W types, and no phase inversion occurred with a temperature change.

\section{Evaluation of the phase inversion by REMPI-TOFMS}

Next, emulsion inversion was evaluated at elevated temperatures using REMPI-TOFMS. In this case, heating of both the sample container and the entire capillary column for sample introduction is a common method. We discussed the possibility, however, that heating the sample container would accelerate the vaporization of the sample. Hence, we devised an approach whereby the phase change of an emulsion might be achieved only by heating the sample introduction outlet, while maintaining the sample container at room temperature.

Figure 5 shows the time profile of the peak area for toluene obtained from a series of mass spectra when measuring an emulsion containing Triton X-100. The sample introduction outlet was heated at either 40 or $80^{\circ} \mathrm{C}$. For comparison, an emulsion containing SDS was also measured under the same experimental conditions; the results are given in Fig. 6.

As shown in Fig. 5, different behaviors were confirmed at outlet temperatures of 40 and $80^{\circ} \mathrm{C}$. Several intense spikes were detected at $40^{\circ} \mathrm{C}$, as shown in Fig. 5(a). This suggested the presence of oil droplets, and therefore the emulsion was determined to be an O/W type. Incidentally, we have reported that such spikes are found when oil droplets with diameters of more than $c a .3 \mu \mathrm{m}$ are present in the case of a toluene-O/W emulsion. ${ }^{30}$

By contrast, when the outlet was heated to $80^{\circ} \mathrm{C}$, no intense 
(a)

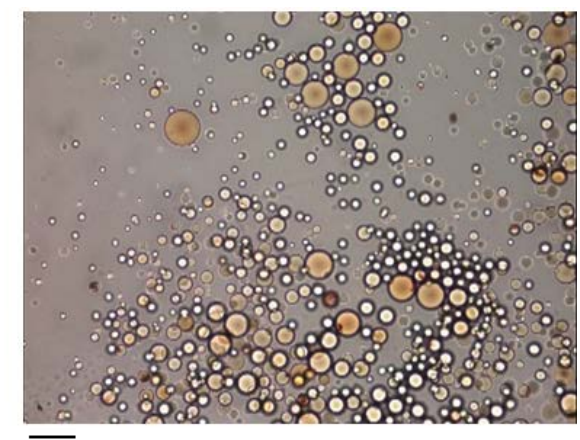

\section{$50 \mu \mathrm{m}$}

(b)

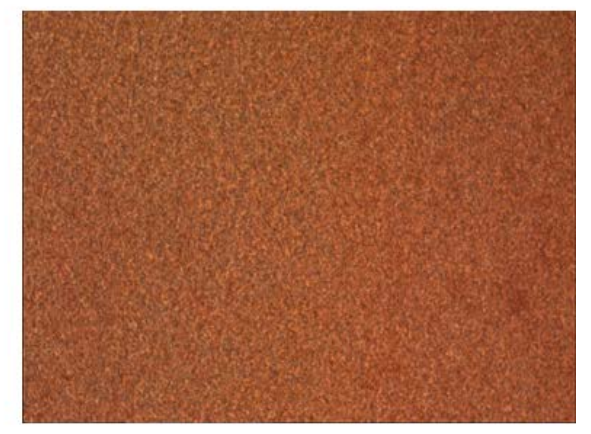

$50 \mu \mathrm{m}$

Fig. 3 Microscopic images of emulsions containing Triton X-100. Temperatures: (a) $40^{\circ} \mathrm{C}$, (b) $80^{\circ} \mathrm{C}$; the actual temperature of each sample was considered to have slightly decreased during observation (see text).

(a)

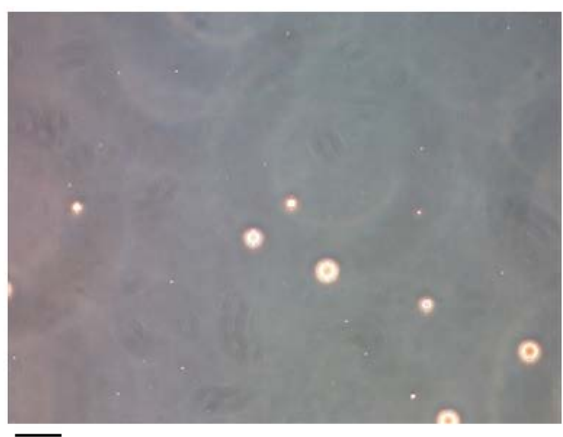

$50 \mu \mathrm{m}$

(b)

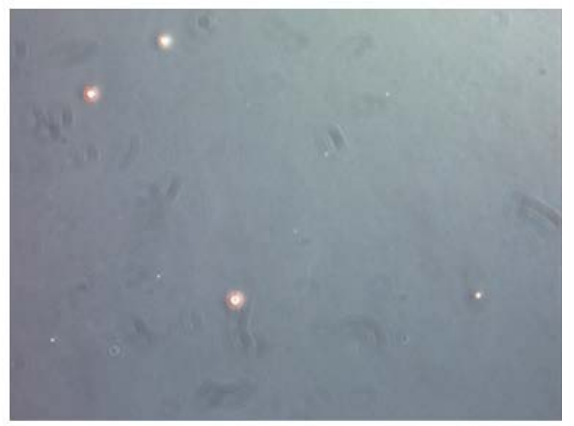

$50 \mu \mathrm{m}$

Fig. 4 Microscopic images of emulsions containing SDS. Temperatures: (a) $40^{\circ} \mathrm{C}$, (b) $80^{\circ} \mathrm{C}$; the actual temperature of each sample was considered to have slightly decreased during observation (see text).
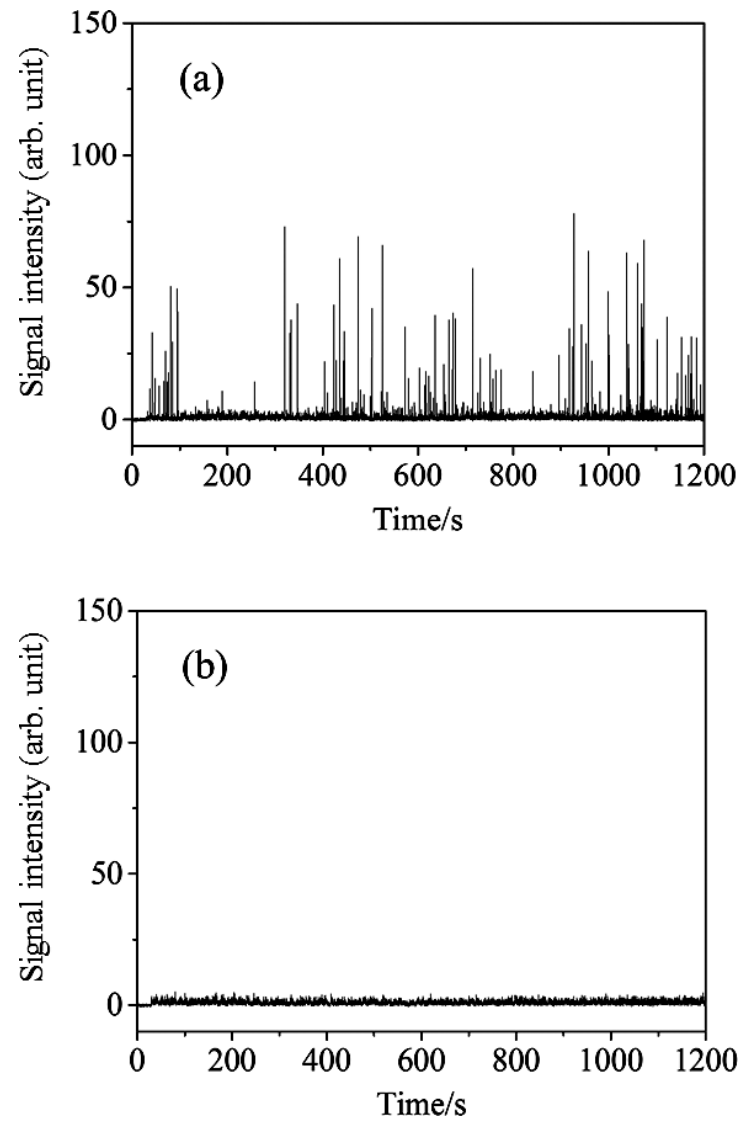

Fig. 5 Time profiles for the peak areas of toluene in an emulsion containing Triton $\mathrm{X}-100$. Temperatures of the sample introduction outlet: (a) $40^{\circ} \mathrm{C}$, (b) $80^{\circ} \mathrm{C}$.

spikes could be found, and less-deviated signals were detected (Fig. 5(b)). The oil droplets were assumed to have shrunk, or even disappeared, when the outlet was heated to $80^{\circ} \mathrm{C}$. There is a possibility that negative spikes can be detected in cases where the phase inversion to a W/O type occurs. However, as shown in Fig. 5(a), with the exception of spikes the signal intensities were very small at $40^{\circ} \mathrm{C}$, and though the spike intensities were strong, the total area obtained from the spikes rarely contributed to the entire area of the signals in the time profile. As a result, in the case of the result at $80^{\circ} \mathrm{C}$ (Fig. 5(b)), the base signals were hardly increased compared with those at $40^{\circ} \mathrm{C}$, and therefore no negative spikes could be detected.

On the other hand, in the case of an emulsion containing SDS, intense spikes appeared on the time profiles not only at $40^{\circ} \mathrm{C}$, but also at $80^{\circ} \mathrm{C}$ (Fig. 6). These results indicate that oil droplets were present at both temperatures and that these emulsions were both $\mathrm{O} / \mathrm{W}$ types. In this manner, using the present system for temperature change, the phase inversion of an emulsion containing a nonionic surfactant can surely be produced.

From the obtained results, an emulsion using Triton X-100 as an emulsifier was assumed to be phase-inverted at $80^{\circ} \mathrm{C}$. A detailed analysis of phase inversion will be discussed in forthcoming papers that will confirm the relationship with temperature that can be continuously increased, and by obtaining a time profile. By increasing the outlet temperature with this technique, the spike intensity should decrease due to the decrease in the droplet diameter. We have proposed a relationship between the droplet diameter and the signal intensity of the spike that appears on a time profile. ${ }^{16,30}$ Therefore, this technique should offer information concerning 

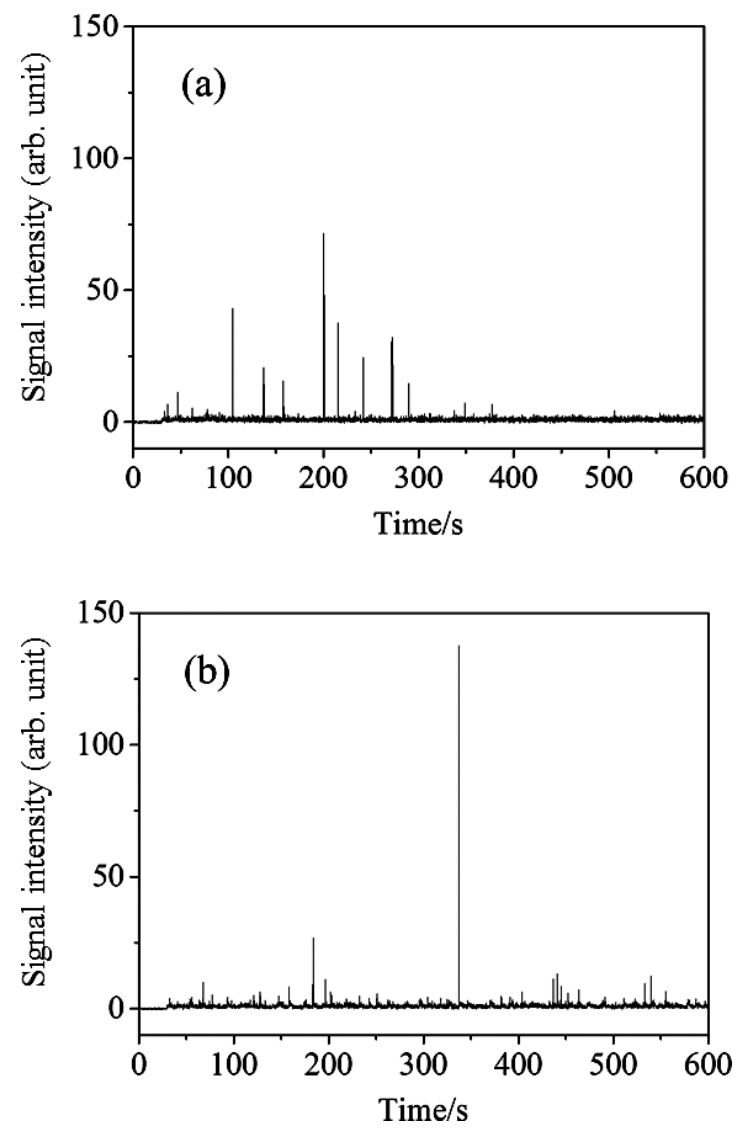

Fig. 6 Time profiles for the peak areas of toluene in an emulsion containing SDS. Temperatures of the sample introduction outlet: (a) $40^{\circ} \mathrm{C}$, (b) $80^{\circ} \mathrm{C}$.

the relationship between the temperature and the droplet diameter. Moreover, this system could inherently eliminate the influence that vaporization exerts on components. Therefore, this method based on REMPI-TOFMS would be useful for evaluating the phase inversion of an emulsion via temperature change.

\section{Conclusions}

The present study demonstrated a new analytical method based on REMPI-TOFMS for evaluating the phase inversion of an emulsion via temperature change. REMPI-TOFMS has several advantages for measuring an emulsion. For example, an online measurement can be achieved without any pretreatment. Moreover, even in the case of emulsion inversion at elevated temperatures, only the sample introduction outlet was heated, while the sample container was kept at room temperature, which suppressed volatilization of the constituents. In future studies, we will confirm the relationship between the temperature and the time profile of the peak areas of constituents; we have reported that gas samples could be measured even at an outlet temperature of $300^{\circ} \mathrm{C} .^{25}$ Moreover, TOFMS is a non-scanning type MS that can evaluate the behavior of individual components during temperature change, which cannot be achieved either by other analytical methods, such as microscopy or via the use of a conductivity meter. Therefore, the present technique should surely be useful for a detailed evaluation of emulsion inversion via temperature change.

\section{References}

1. J. Israelachvili, Colloids Surf., A, 1994, 91, 1.

2. L. Yu, C. Li, J. Xu, J. Hao, and D. Sun, Langmuir, 2012, $28,14547$.

3. A. Forgiarini, J. Esquena, C. González, and C. Solans, Prog. Colloid Polym. Sci., 2001, 118, 184.

4. A. Pizzino, M. P. Rodriguez, C. Xuereb, M. Catté, E. van Hecke, J.-M. Aubry, and J. L. Salager, Langmuir, 2007, 23, 5286.

5. K. Roger, B. Cabane, and U. Olsson, Langmuir, 2010, 26, 3860.

6. F. Bouchama, G. A. van Aken, A. J. E. Autin, and G. J. M. Koper, Colloids Surf., A, 2003, 231, 11.

7. K. Shinoda and H. Arai, J. Phys. Chem., 1964, 68, 3485.

8. T. Iwanaga, M. Suzuki, and H. Kunieda, Langmuir, 1998, 14,5775 .

9. J. Rao and D. J. McClements, J. Agric. Food Chem., 2010, 58,7059 .

10. J. Allouche, E. Tyrode, V. Sadtler, L. Choplin, and J.-L. Salager, Langmuir, 2004, 20, 2134.

11. P. Izquierdo, J. Esquena, T. F. Tadros, J. C. Dederen, J. Feng, M. J. Garcia-Celma, N. Azemar, and C. Solans, Langmuir, 2004, 20, 6594.

12. H. Ishigami, Y. Tsuda, and T. Uchimura, Anal. Methods, 2014, 6, 5615.

13. H. Fukaya, Y. Tsuda, and T. Uchimura, Anal. Methods, 2016, 8, 270.

14. Y. Tsuda and T. Uchimura, Anal. Sci., 2016, 32, 789.

15. H. Yamamoto, H. Ishigami, and T. Uchimura, Anal. Sci., 2017, 33, 731 .

16. C. Fujita, Y. Sugimura, and T. Uchimura, Appl. Sci., 2018, $8,413$.

17. D. M. Lubman and M. N. Kronick, Anal. Chem., 1982, 54, 660.

18. J. Matsumoto, C.-H. Lin, and T. Imasaka, Anal. Chem., 1997, 69, 4524.

19. O. P. Haefliger and R. Zenobi, Anal. Chem., 1998, 70, 2660.

20. F. Gunzer, S. Krüger, and J. Grotemeyer, Mass Spectrom. Rev., 2019, 38, 202.

21. R. Zenobi, J.-M. Philippoz, P. R. Buseck, and R. N. Zare, Science, 1989, 246, 1026.

22. T. Imasaka, M. Hozumi, and N. Ishibashi, Anal. Chem., 1992, 64, 2206.

23. R. B. Opsal and J. P. Reilly, Anal. Chem., 1988, 60, 1060.

24. S. C. Owens, J. A. Berenbeim, M. R. Ligare, L. E. Gulian, F. M. Siouri, S. Boldissar, S. Tyson-Smith, G. Wilson, A. Ford, and M. S. de Vries, Anal. Chem., 2017, 89, 2838.

25. T. Fujii and T. Uchimura, Anal. Methods, 2015, 7, 2611.

26. S. Otto, S. Erdmann, T. Streibel, D. P. R. Herlemann, D. Schulz-Bull, and R. Zimmermann, Anal. Methods, 2016, 8, 2592.

27. U. Boesl, Mass Spectrom. Rev., 2017, 36, 86.

28. A. Hamachi, T. Imasaka, H. Nakamura, A. Li, and T. Imasaka, Anal. Chem., 2017, 89, 5030.

29. C. Kruth, H. Czech, M. Sklorz, J. Passig, S. Ehlert, A. Cappiello, and R. Zimmermann, Anal. Chem., 2017, 89, 10917.

30. Y. Shimo and T. Uchimura, Anal. Sci., 2016, 32, 1059.

31. H. Fukaya and T. Uchimura, Anal. Sci., 2017, 33, 1067.

32. R. Shinoda and T. Uchimura, ACS Omega, 2018, 3, 13752.

33. E. H. Liu, P. T. Callaghan, and K. M. McGrath, Langmuir, 2003, 19, 7249.

34. K. Shinoda and H. Saito, J. Colloid Interface Sci., 1968, 26, 70.

35. A. Pizzino, V. Molinier, M. Catté, J. F. Ontiveros, J.-L. Salager, and J.-M. Aubry, Ind. Eng. Chem. Res., 2013, 52, 4527.

36. W. Chen, X. Liu, Y. Liu, Y. Bang, and H.-I. Kim, J. Ind. Eng. Chem., 2011, 17, 455. 